\title{
Сорбция ионов молибдена (VI) новыми синтетическими сорбентами
}

\author{
Ергожин Е.Е., Чалов Т.К., Ковригина Т.В., Мельников Е.А. \\ АO «Институт химических наук им. А.Б. Бектурова», Алмать
}

Поступила в редакцию 22.02.2018 г.

DOI: https://doi.org/10.17308/sorpchrom.2018.18/533

Изучена сорбция ионов молибдена (VI) новыми анионитами на основе 4,4оксиэтилендиамина и некоторых полиаминов. Установлено, что они обладают высокими сорбционными свойствами по отношению к ионам молибдена. Как показали исследования, синтезированные иониты обладают высокой обменной емкостью - до 11,0 мг-экв $\Gamma^{-1}$ и, соответственно, повышенной сорбционной способностью. Хорошая устойчивость в агрессивных химических средах $\left(5 \mathrm{H} \mathrm{H}_{2} \mathrm{SO}_{4}\right.$, $\mathrm{NaOH})$ и при температурных воздействиях допускает возможность их использования в различных технологических схемах. Состав и структуру комплексообразующего анионита исследовали методами ИК-спектроскопии и элементного анализа.

Ключевые слова: сорбционная емкость, ионный обмен, статические условия, ионы молибдена, изотерма сорбции.

\section{Sorption of molybdenum ions (VI) by new synthetic sorbents}

\author{
Ergozhin E.E., Chalov T.K., Kovrigina T.V., Melnikov Ye.A. \\ JSC «Institute of Chemical Sciences named A.B. Bekturov», Almaty
}

\begin{abstract}
Methods for the synthesis of new anion exchangers based on glycidyl derivatives of 4.4'oxydianiline and certain polyamines have been developed, and the optimum conditions for their preparation have been found. The composition and structure of the complexing ion exchangers were studied by IR spectroscopy and elemental analysis. Synthesized ion exchangers have a high exchange capacity - up to $11.0 \mathrm{mg}-$ $\mathrm{eq} \cdot \mathrm{g}^{-1}$ and, accordingly, increased sorption capacity. It is established that they have high chemical and thermal stability. The loss of their capacity in solutions of acids and alkalis does not exceed $2-8 \%$, and in solutions of oxidizing agents it is $50-52 \%$. Good stability in aggressive chemical environments $\left(5 \mathrm{~N} \mathrm{H}_{2} \mathrm{SO}_{4}\right.$, $\mathrm{NaOH})$ and at temperature influences allows their use in various technological schemes. The method of classical polarography under static conditions has been used to study sorption of molybdenum (VI) ions by new anion exchangers based on 4.4-oxyethylenediamine and some polyamines. During the research, regimes of sorption experiments (sorbent-solution ratio, concentration and $\mathrm{pH}$ of molybdenum-containing model solutions and contact time), close to industrial ones, were chosen. It is established that they possess high sorption properties with respect to molybdenum (VI) ions. A sharp rise in sorption isotherms at low equilibrium concentrations indicates that these ions can be used to extract molybdenum ions with sufficient completeness. At the same time, the extraction rate reaches $77 \%$. It has been found that the anion exchange resin based on polyethylene polyamine has a higher sorption capacity, its sorption capacity is 230.4 , and in the case of polyethyleneimine it is $211.2 \mathrm{mg} \cdot \mathrm{g}^{-1}$. It is shown that the acidity of the medium in the $\mathrm{pH}$ range $1.0-8.3 \mathrm{has}$ a significant effect on the sorption of molybdate ions. Found that the obtained ion exchangers have higher kinetic properties than industrial ones, and complete chemical equilibrium occurs in 3 hours. At the same time, their sorption capacity is 460.8 and $422.4 \mathrm{mg} \cdot \mathrm{g}^{-1}$, respectively.
\end{abstract}

Keywords: sorption capacity, ion exchange, static conditions, molybdenum ions, sorption isotherm. 


\section{Введение}

Потребность в молибдене, обладающим уникальными свойствами, привела к необходимости развития производства и непрерывного расширения методов его получения. Производство молибдена в основном осуществляется за счет переработки концентратов, полученных при фильтрации молибденовых руд. Большие его количества теряются при получении и обработке сплавов (сопутствующие ионы $\mathrm{Cl}^{-}, \mathrm{SO}_{4}{ }^{2-}$, $\mathrm{NO}_{3}{ }^{-}$). До сих пор для выделения молибдена из сбросных растворов и отходов используют метод его осаждения в виде неорганических и органических соединений. Перед осаждением необходимо иметь представление о состоянии молибдат-иона в растворах в зависимости от кислотности среды и концентрации ионов $\mathrm{Cl}^{-}, \mathrm{SO}_{4}{ }^{2-}$ и $\mathrm{NO}_{3}^{-}$, поскольку знание формы молибдена в растворе обеспечивает быстрый и эффективный выбор метода выделения его из растворов [1].

Сжигание щелочных отходов исключает из материального оборота до 35 тонн в год дорогого и дефицитного молибдена, что влечет безвозвратную потерю его органической части, являющейся ценным нефтехимическим сырьем, и образованию значительных вредных выбросов [2]. При осуществлении селективных процессов с целью концентрирования или разделения целевых компонентов, особенно эффективен анионный обмен, но только в том случае, если ионы металлов находятся в виде анионных комплексов. Среди указанных металлов важное место занимают молибден, рений, вольфрам, ванадий и др. [3].

Для переработки молибденовых и вольфрамовых концентратов применяют гидрометаллургические и пирометаллургические методы. К гидрометаллургическим относятся автоклавно-содовое выщелачивание, выщелачивание $\mathrm{NaOH}$, разложение азотной, соляной и серной кислотами. К пирометаллургическим методам относится спекание с различными солями щелочных металлов с последующим переводом вольфрама и молибдена в азотнокислые или солянокислые растворы. Гидрометаллургические методы разложения концентратов и промпродуктов удобно сочетать с последующим извлечением рения, молибдена и вольфрама экстракцией и ионообменной сорбцией.

Широкое применение редких цветных металлов требует вовлечения в промышленность все большего их количества. Поэтому использование вторичного сырья в современном производстве быстро и неуклонно растет [4].

Для определения молибдена (VI) чаще всего используют экстракционнофотометрический и электрохимический методы [5-8]. Однако, в первом из них требуются довольно большие объемы органических экстрагентов, а во втором, как правило, открытой ртути, что не соответствует возросшим требованиям к экологической безопасности анализа. Другие методы определения молибдена - нейтронноактивационный и масс-спектрометрия с индуктивно связанной плазмой, используют редко из-за довольно высокой стоимости анализа [9]. В связи с этим определенный интерес представляют собой комбинированные методы, сочетающие в одном приеме тестирование на присутствие молибдена по образованию окрашенных соединений и их концентрирование на различных сорбентах. С этой целью в последнее время широко применяют сорбционно-фотометрические методы с использованием полимерных хелатных сорбентов $[10,11]$.

Целью работы является исследование закономерностей сорбции молибдатионов анионитами на основе эпоксидных производных 4,4'-оксидианилина и некоторых полиаминов.

$\boldsymbol{E}$ ргожин и др. / Сорбционные и хроматографические процессы. 2018. Т. 18. № 3 


\section{Эксперимент}

На первом этапе из 4,4'-оксидианилина (ОДА) и эпихлоргидрина (ЭХГ) в присутствии едкого натра при температуре $80^{\circ} \mathrm{C}$ в течении 6 ч синтезировали глицидиловые производные аминов по следующей схеме:<smiles>COC(=O)N(CC1CO1)c1ccc(Oc2ccc(N(CC3CO3)CC3CO3)cc2)cc1</smiles>

На втором этапе проводили их конденсацию с полиэтиленимином (ПЭИ) и полиэтиленполиамином (ПЭПА) при различных массовых соотношениях в растворе диметилформамида (ДМФА). Температура реакции $-60^{\circ} \mathrm{C}$, продолжительность - 34 ч. Затем полученную реакционную массу отверждали при $100{ }^{\circ} \mathrm{C}$ в течение $12-15$ ч и получали анионит пространственного строения с размерами частиц 0,5-1,0 мм и 97\%-ным выходом. Предварительно нами были изучены и найдены оптимальные условия синтеза ионообменников. Схемы получения ионообменников на основе ОДА с некоторыми полиаминами представлены ниже:
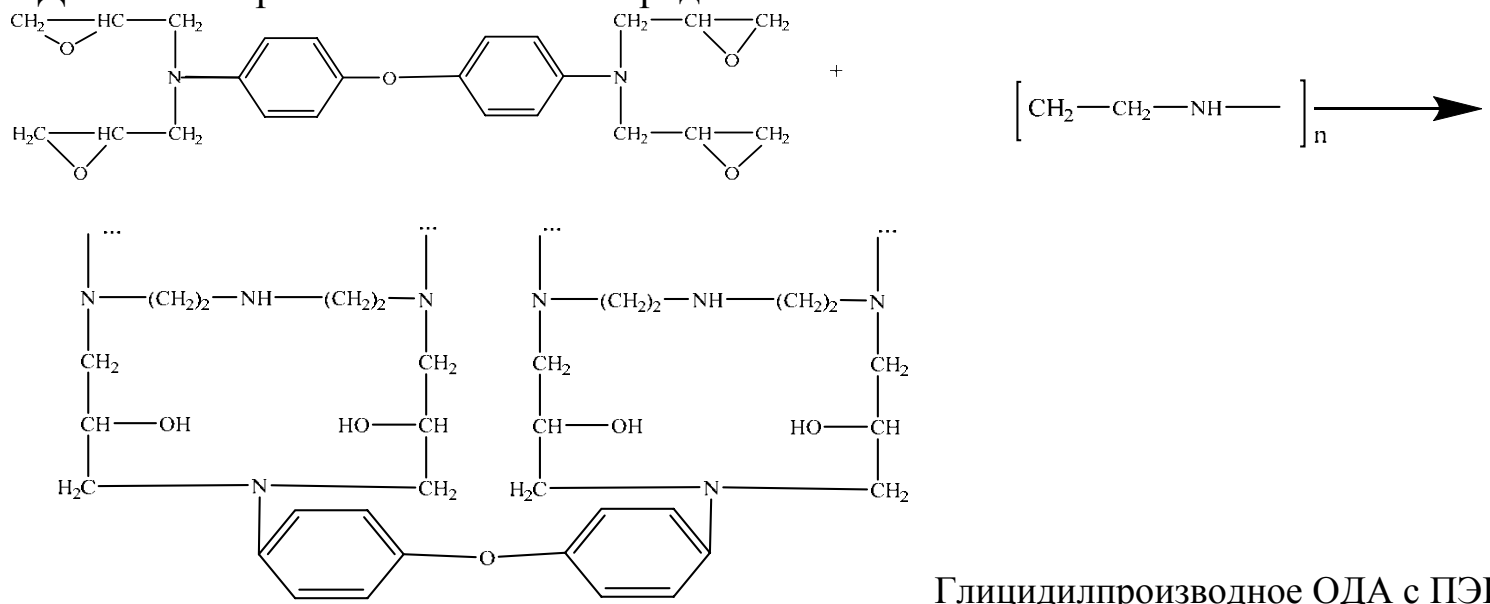

Глицидилпроизводное ОДА с ПЭИ

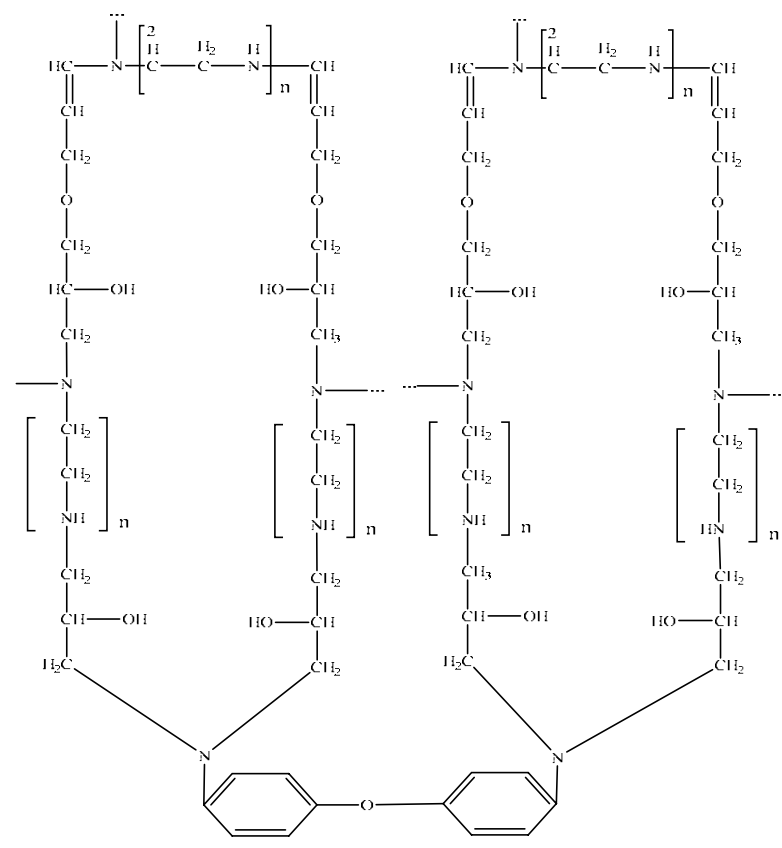

ОДА-ПЭПА 
Состав и химическую структуру полученных комплексообразующих ионитов исследовали методами ИК-спектроскопии на ИК Фурье-спектрометре Nicolet 5700 (Thermo Electron Corporation, CША) и элементного анализа на анализаторе CHN628 (LECO, СШA).

На рис. 1 представлены спектры синтезированных комплексообразующих анионитов. Видно, что в спектрах отсутствуют характеристические частоты (cм $\left.{ }^{-1}\right)$ эпоксидных групп (825-948, 1249, 3000-3040), что свидетельствует об их химическом превращении. Появляются сильные полосы поглощения при частоте 1109 валентных колебаний эфирной группы $\mathrm{C}-\mathrm{O}-\mathrm{C}$ и $\mathrm{C}-\mathrm{N}$ связей и полосы поглощения, соответствующие деформационным $(1516)$ и валентным $(2286,2852,2924)$ колебаниям NH-групп. Кроме того, в спектре присутствуют характеристические частоты деформационных колебаний $\mathrm{CH}_{2}$-групп (1453) и валентных колебаний $\mathrm{OH}$ и $\mathrm{NH}$-групп (3409), а также полосы деформационных колебаний $\mathrm{CH}=\mathrm{CH}$ связей (1614).

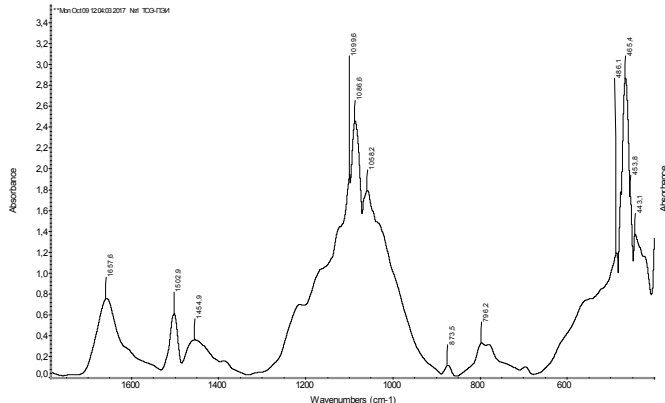

a

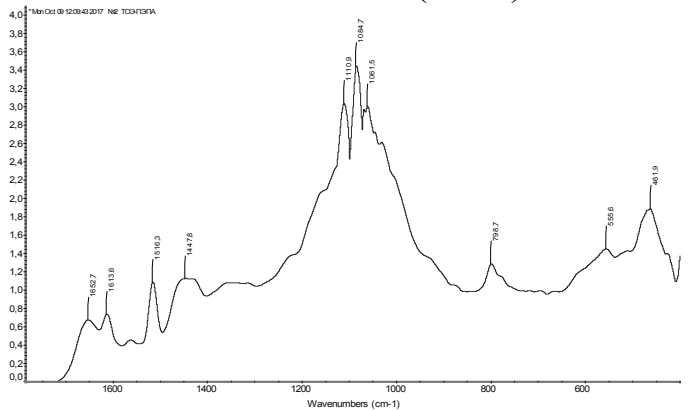

6

Рис. 1. ИК спектры ионитов на основе ОДА-ПЭИ (а) и ОДА-ПЭПА (б)

Элементный анализ (рассчитано/найдено) для ОДА-ПЭИ \%: С - 61.86/61.14; H - 9.18/9.82; N - 14.64/14.36; О - 14.33 /14.67; для ОДА-ПЭПА \%: С - 61.64/61.36; Н - 9.90/9.1; N - 14.38/14.62; О - 14.08/14.92. В таблице 1 представлены основные физико-химические свойства синтезированных ионообменников.

Таблица 1. Основные физико-химические свойства полученных анионитов

\begin{tabular}{|c|c|c|c|c|c|c|c|c|c|}
\hline \multirow{3}{*}{$\begin{array}{c}\text { Анионит на } \\
\text { основе }\end{array}$} & \multirow{3}{*}{$\begin{array}{l}\mathrm{COE}_{\mathrm{HCl}} \\
\text { мГ-ЭКВ } \Gamma^{-1}\end{array}$} & \multirow{3}{*}{$\begin{array}{l}\mathrm{V}_{\text {уд, }} \\
\mathrm{cm}^{3} \cdot \Gamma^{-1}\end{array}$} & \multirow{3}{*}{$\begin{array}{l}\mathrm{W}, \\
\%\end{array}$} & \multicolumn{3}{|c|}{$\begin{array}{c}\text { Химическая } \\
\text { устойчивость в растворах }\end{array}$} & \multirow{2}{*}{\multicolumn{3}{|c|}{$\begin{array}{c}\text { Термическая } \\
\text { устойчивость } \\
\text { в воде, \% }\end{array}$}} \\
\hline & & & & $5 \mathrm{H}$ & $5 \mathrm{H}$ & $10 \%$ & & & \\
\hline & & & & $\mathrm{H}_{2} \mathrm{SO}_{4}$ & $\mathrm{NaOH}$ & $\mathrm{H}_{2} \mathrm{O}_{2}$ & 24 ч & 364 & 48 ч \\
\hline & & 5.6 & 69 & 95 & 98 & 50 & 9 & 94 & 94 \\
\hline ОДА-ПЭПА & 11.0 & 5.4 & 71 & 96 & 96 & 48 & 99 & 98 & 98 \\
\hline
\end{tabular}

Примечание: $\mathrm{COE}_{\mathrm{HCl}}$ - статическая обменная емкость по 0,1 н р-ру $\mathrm{HCl}, \mathrm{V}_{\text {уд. }}$ - удельный объем (набухаемость), W - влажность.

Одним из основных показателей ионитов является их химическая устойчивость, о которой судили по изменению статической обменной емкости (COE) после контакта с 5 н растворами $\mathrm{H}_{2} \mathrm{SO}_{4}, \mathrm{NaOH}, 10 \% \mathrm{H}_{2} \mathrm{O}_{2}$ [12]. Представленные табличные данные свидетельствуют о высокой устойчивости синтезированных ионообменников к действию кислот и щелочей. Потери их емкости в растворах не превышают 2-8\%, а в растворах окислителей - 50-52\%.

\section{Обсуждение результатов}

В ходе проведенных исследований установлено, что синтезированные иониты обладают повышенной статической обменной емкостью (СОЕ до 11.0 мГ-экв $\left.\Gamma^{-1}\right)$ и 
имеют хорошую устойчивость в агрессивных химических средах, а также при температурных воздействиях, что позволит использовать их в различных технологических режимах.

Нами в статических условиях исследована сорбция молибдат-ионов на синтезированных ионитах. Содержание молибдена в исходных и равновесных растворах определяли методом классической полярографии на фоне 0.5 н $\mathrm{H}_{2} \mathrm{SO}_{4}$ по волне восстановления $\mathrm{Mo}^{6+}\left(\mathrm{E}_{1 / 2}=-0.27 \mathrm{~B}\right)$. Полярограммы регистрировали на универсальном полярографе ПУ-1 с погрешностью измерений $\pm 0.5 \%$ в термостатированной ячейке при температуре $25 \pm 0.5^{\circ} \mathrm{C}$, используя ртутный капающий электрод. Кислород из анализируемых растворов удаляли путем продувания аргона в течение 5 мин. В качестве электрода сравнения служил насыщенный каломельный электрод. Были выбраны режимы сорбционных экспериментов (соотношение сорбент-раствор, концентрация и рН молибденсодержащих модельных растворов и время контакта), близкие к промышленным. Количество сорбированного металла (сорбционную емкость (СЕ)) рассчитывали по разнице между концентрацией молибдена в исходном растворе и фильтрате после сорбции.

Молибдат-ионы извлекали при комнатной температуре $20 \pm 2^{\circ} \mathrm{C}$ и периодическом перемешивании 0.05 г полимерного комплексообразующего сорбента с $20 \mathrm{~cm}^{3}$ раствора $\mathrm{Na}_{2} \mathrm{MoO}_{4}$, варьируя концентрацию в растворах $\mathrm{Na}_{2} \mathrm{MoO}_{4}$ от 0.216 до 2.016 г/дм ${ }^{3}$ и изменяя их кислотность добавлением 5 н раствора $\mathrm{H}_{2} \mathrm{SO}_{4}$ в пределах $\mathrm{pH}$ от 1.0 до 8.3 .

Из рис.2, где представлены изотермы сорбции молибдат-ионов, видно, что СЕ анионитов возрастает с повышением их содержания в растворах. Резкий подъем кривых при малых равновесных концентрациях свидетельствует о том, что данными ионообменниками можно извлекать ионы молибдена с достаточной полнотой. Степень извлечения при этом достигает 77\%.

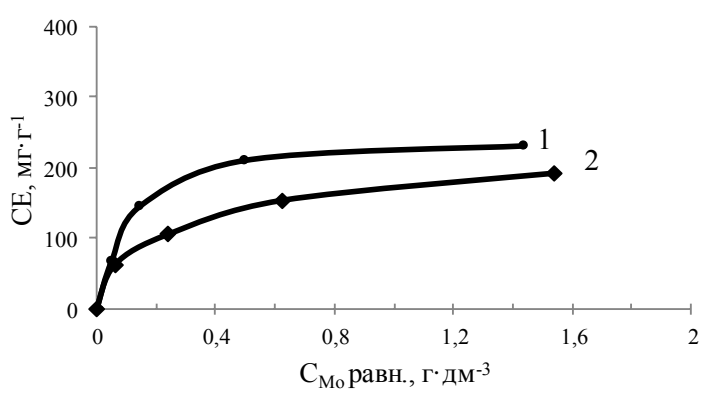

Рис. 2. Изотермы сорбции молибдат-ионов: ОДА-ПЭПА (1) и ОДА-ПЭИ (2)

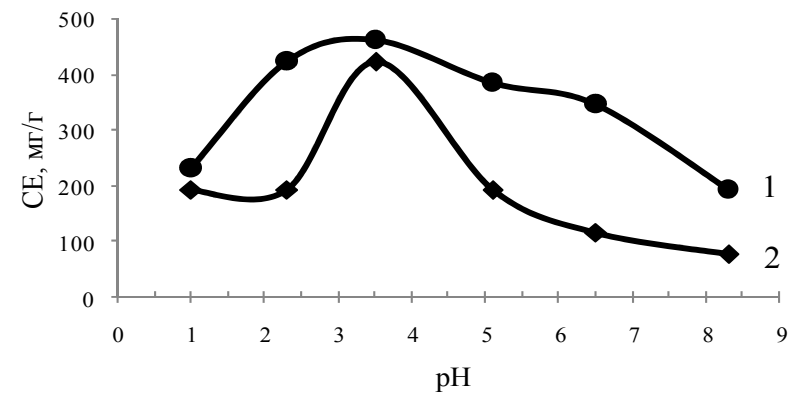

Рис. 3. Зависимость сорбционной емкости синтезированных анионитов от кислотности раствора $\mathrm{Na}_{2} \mathrm{MoO}_{4}$ : ОДА-ПЭПА (1) и ОДА-ПЭИ (2)

Найдено, что более высокой сорбционной способностью обладает анионит на основе ПЭПА, его СЕ составляет 230.4 мг $\Gamma^{-1}$, а в случае применения ПЭИ $211.2 \mathrm{M \Gamma}^{\cdot} \Gamma^{-1}$.

Одним из важнейших факторов при сорбционном извлечении ионов металлов из раствора является значение кислотности среды, влияющее как на форму, в которой находится в растворе исследуемый ион, так и на состояние ионогенных групп [13]. Из рис. 3, где представлены кривые, описывающие зависимость СЕ молибдатионов анионитов от кислотности растворов $\mathrm{Na}_{2} \mathrm{MoO}_{4}$, видно, что оптимальным значением $\mathrm{pH}$ для их извлечения является 3.5. В этих условиях происходит максимальное поглощение молибдат-ионов и СЕ ионитов на основе ОДА-ПЭПА и ОДА-ПЭИ 
равняется соответственно 460.8 и 422.4 мг Мо $\Gamma^{-1}$. На рис. 4 представлены изотермы сорбции молибдат-ионов анионитами на основе ОДА-ПЭПА и ОДА-ПЭИ.

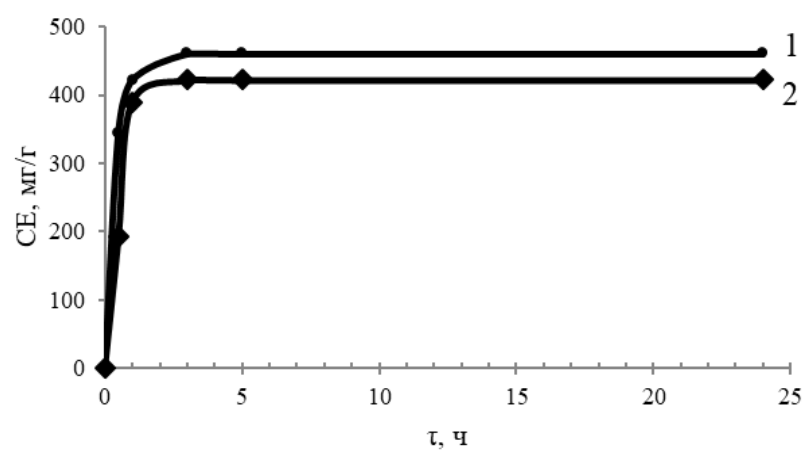

Рис. 4. Зависимость сорбционной емкости синтезированных анионитов от продолжительности контакта с раствором $\mathrm{Na}_{2} \mathrm{MoO}_{4}$ :

ОДА-ПЭПА (1) и ОДА-ПЭИ (2)

Равновесное состояние между ионитами и раствором, содержащим 0.672 г/дм ${ }^{3}$ молибдена и имеющим $\mathrm{pH} 3.5$, наступает через 3 ч. При этом их СЕ составляет 460.8 и 422.4 мг $^{-1} \Gamma^{-1}$ соответствено.

В работе [14] установлено, что промышленный анионит марки АМП, содержащий обменные группы $-\mathrm{CH}_{2}-\mathrm{N}^{+}<$, аналогично синтезированным нами ионообменникам, максимально извлекает молибдат-ионы в кислых средах $(\mathrm{pH}=3)$. Полное сорбционное равновесие на анионите АМП устанавливается за 7 суток, а СЕ про-

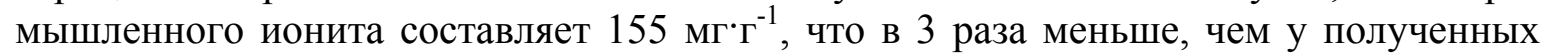
нами ионообменников, показавших наилучшие результаты в сильнокислой среде при $\mathrm{pH}=3.5$ и СЕ которых равны 460.8 и 422.4 мг $\Gamma^{-1}$, соответственно, что свидетельствует об их более высоких кинетических свойствах.

\section{Заключение}

Исследованы сорбционные свойства новых ионитов на основе эпоксидных производных 4,4'-оксидианилина и некоторых полиаминов по отношению к молибдат-ионам. Установлено, что они обладают высокими сорбционными свойствами при их извлечении из индивидуальных модельных растворов $\mathrm{Na}_{2} \mathrm{MoO}_{4}$. Показано, что кислотность среды в интервале $\mathrm{pH}=1.0-8.3$ оказывает существенное влияние на сорбцию ионов молибдена (VI). Полученные аниониты на основе ОДА-ПЭПА и ОДА-ПЭИ обладают более высокими кинетическими свойствами по сравнению с промышленными, а полное химическое равновесие наступает через 3 ч.

Работа выполнена по гранту Комитета науки Министерства образования и науки Республики Казахстан № АР05131439 на тему «Синтез и модификаиия наноструктурных ионообменных мембран и создание на их основе инновационных систем водоподготовки».

\section{Список литературы}

1. Умарахунов М.Х., Садыкова У.А., Ходжаева Г.А. // Журнал физической химии. 2011. T. 85. № 2. С. 391-393.

2. Самодуров В.М., Клушин В.Н. // Усnехи в химии и химической технологии. 2014. Т. 28. № 5. C. 62-65.
3. Эшкурбонов Ф.Б., Джалилов А.Т. // Инноващии в науке. 2013. № 27. С. 41-46.

4. Неудачина Л.К., Петрова Ю.С., Засухин А.С.и др. // Аналитика и контроль. 2011. Т. 15. № 1. C. 87-95. 
6. Sanchez-Vinas M., Bagur G.M., Gazquez D., Camino M. et al. // Journal of Analytical Toxicology. 1999. Vol.23. No 2. pp.108-112.

7. Agrawal Y.K., Menon S.K., Patel K.R. // Mikrochim. Acta. 1996. Vol.122. No 3-4. pp. 259-265.

8. Слепченко Г.Б., Пикула Н.П., Дубова Н.М. // Известия Томского политехнического университета. Вестник Томского политехнического университета. 2009. Т. 314. № 3. C.59-70.

9. Nomngongo P.N., Ngila J.C., Kamau J.N., Msagati T.A. et al.// Talanta. 2013. Vol. 110. pp. 153-159.

10. Azeredo L.C., Aparecida M.A., Castro R.N., Saldanha M.C. et al. // Spectrochimica
Acta, Part B. 2002. Vol. 57. No 12. pp. 21812185.

11. Kononova O.N., Kachin S.V., Chaikovskaya A.E., Kholmogorov A.G. et al. // Turk J Chem. 2004. Vol. 28. pp. 193-202.

12. Салдадзе К.М., Пашков А.Б., Титов В.С. Ионообменные высокомолекулярные соединения. М. Госхимиздат. 1960. 355 с.

13. Ergozhin E.E., Chalov T.K., Kovrigina T.V., Melnikov E.A., Nikitina A.I. // Russian Journal of Applied Chemistry. 2017. Vol. 90. No 5. pp. 769-774.

14. Пат. РФ 2229530 (опубл. 27.05.2004). Способ сорбции молибдена (VI).

\section{References}

1. Umarahunov M.H., Sadykova Yu.A., Hodzhaeva G.A., Zhurnal fizicheskoj himii, 2011, Vol. 85, No 2, pp. 391-393.

2. Samodurov V.M., Klushin V.N., Uspehi v himii $i$ himicheskoj tehnologii, 2014, Vol. 28I, No 5, pp. 62-65.

3. Jeshkurbonov F.B., Dzhalilov A.T., Innovacii v nauke, 2013, No 27, pp. 41-46.

4. Neudachina L.K., Petrova Ju.S., Zasuhin A.S. et al., Analitika $i$ kontrol', 2011, Vol. 15, No 1, pp. 87-95.

6. Sanchez-Vinas M., Bagur G.M., Gazquez D., Camino M., Romero R., Journal of Analytical Toxicology, 1999, Vol. 23, No 2, pp. 108-112.

7. Agrawal Y.K., Menon S.K., Patel K.R., Mikrochim. Acta, 1996, Vol. 122, No 3-4, pp. 259-265.

8. Slepchenko G.B., Pikula N.P., Dubova N.M., Izvestija Tomskogo politehnicheskogo universiteta. Vestnik Tomskogo

Ергожин Едил Ергожаевич - академик НАН РК, д.Х.Н., профессор, заведующий лабораторией Ионообменных смол и мембран, Генеральный директор АО «Институт химических наук им. А.Б. Бектурова», Алматы

Чалов Тулеген Каменович - д.Х.н., профессор, главный научный сотрудник лаборатории Ионообменных смол и мембран, Алматы

Ковригина Татьяна Васильевна - к.х.н., ассоциированный профессор, ведущий научный сотрудник лаборатории Ионообменных смол и мембран, Алматы

Мельников Евгений Александрович - $\mathrm{PhD}$, научный сотрудник лаборатории Ионообменных смол и мембран, Алматы politehnicheskogo universiteta, 2009, Vol. 314, No 3, pp .59-70.

9. Nomngongo P.N., Ngila J.C., Kamau J.N., Msagati T.A. et al., Talanta, 2013, Vol. 110, pp. 153-159.

10. Azeredo L.C., Aparecida M.A., Castro R.N., Saldanha M.C. et al., Spectrochimica Acta, Part B, 2002, Vol. 57, No 12, pp.21812185.

11. Kononova O.N., Kachin S.V., Chaikovskaya A.E., Kholmogorov A.G. et al., Turk J Chem., 2004, Vol. 28, pp.193-202.

12. Saldadze K.M., Pashkov A.B., Titov V.S., Ionoobmennye vysokomole-kulyarnye soedineniya, M., Goskhimizdat, 1960, 355 p.

13. Ergozhin E.E., Chalov T.K., Kovrigina T.V., Melnikov E.A. et al., Russian Journal of Applied Chemistry, 2017, Vol. 90, No 5, pp. 769-774.

14. Pat. RF 2229530 (opubl. 27.05.2004). Sposob sorbcii molibdena

(VI).

Ergozhin Edil E. - academician of National Academy of Sciences of Kazakhstan, Dr. Sci. (Chemistry), professor, chief of the Laboratory of ion exchange resins and membranes, General director of the JSC "Institute of Chemical Sciences named after A.B. Bekturov", Almaty

Chalov Tulegen K. - Dr. Sci. (Chemistry), professor, chief researcher at the Laboratory of ion exchange resins and membranes, Almaty

Kovrigina Tatyana V. - Candidate of Chemistry, associated professor, leading researcher at the Laboratory of ion exchange resins and membranes, Almaty, e-mail: kovriginatat@mail.ru

Melnikov Yevgeniy A. - PhD, researcher at the Laboratory of ion exchange resins and membranes, Almaty 